\title{
Validity of the Buttoning Test in Hand Disability Evaluation of Patients With Stroke
}

\author{
Youn-Soo Cheong, $\mathrm{MD}^{1}$, Ae Ryoung Kim, $\mathrm{MD}^{1}$, Eunhee Park, $\mathrm{MD}^{1}$, Won-Jong Yang, $\mathrm{MD}^{1}$, \\ Jae-Won Huh, MD ${ }^{1}$, Hyun-Min Oh, MD ${ }^{1}$, Yu-Sun Min, MD $^{1,2}$, Chul-Hyun Kim, MD $^{1,2}$, \\ Tae-Du Jung, $\mathrm{MD}^{1,2}$, Yang-Soo Lee, $\mathrm{MD}^{1,2}$ \\ ${ }^{1}$ Department of Rehabilitation Medicine, Kyungpook National University Hospital, Daegu; \\ ${ }^{2}$ Department of Rehabilitation Medicine, Kyungpook National University School of Medicine, Daegu, Korea
}

Objective To investigate the relationship between the buttoning test and Jebsen-Taylor Hand Function Test (JTHFT), and to determine the validity of using the buttoning test as a tool to evaluate hand disability in patients with stroke.

Methods This was a retrospective study of the medical records of 151 ischemic stroke patients affecting the dominant hand. Patients underwent the buttoning test and JTHFT for their affected hand. All patients were divided into three groups depending on how quickly they fastened a button (group A, not completed; group B, slowly completed over 18 seconds; and group C, completed within 18 seconds).

Results The button fastening time was negatively correlated with the total score and subtest scores of the JTHFT. Patients who experienced difficulty during the buttoning test had lower mean scores in the JTHFT (group A, 28.0 \pm 23.9 ; group $B, 62.9 \pm 21.7$; group $C$, 75.4 \pm 13.3 ; $p<0.0001$, Jonckheere-Terpstra test). We observed significant differences in JTHFT scores among the three groups $(\mathrm{p}<0.017$, Mann-Whitney U-test), although there were considerable overlaps in JTHFT scores between the groups. Significant differences were also found in the subtest scores of the JTHFT, which include fine hand motor function (writing letters, $\mathrm{p}=0.009$; moving small objects, $\mathrm{p}=0.003$; stacking checkers, $\mathrm{p}=0.001$ between groups $\mathrm{B}$ and $\mathrm{C}$ ), among the three groups.

Conclusion Considering its relationship with the JTHFT and validity, the buttoning test can be considered appropriate for evaluation of hand disability in patients with stroke.

Keywords Hand, Paresis, Disability evaluation, Validation studies, Stroke

Received May 19, 2017; Accepted June 28, 2017

Corresponding author: Yang-Soo Lee

Department of Rehabilitation Medicine, Kyungpook National University Hospital, 130 Dongdeok-ro, Jung-gu, Daegu 41944, Korea. Tel: +82-53-2005315, Fax: +82-53-423-0389, E-mail: leeyangsoo@knu.ac.kr

ORCID: Youn-Soo Cheong (https://orcid.org/0000-0001-7105-4776); Ae Ryoung Kim (https://orcid.org/0000-0003-3765-3024); Eunhee Park (https:// orcid.org/0000-0001-6553-2321); Won-Jong Yang (https://orcid.org/0000-0002-2711-3318); Jae-Won Huh (https://orcid.org/0000-0002-3351-6340); Hyun-Min Oh (https://orcid.org/0000-0001-8092-3443); Yu-Sun Min (https://orcid.org/0000-0003-0373-0538); Chul-Hyun Kim (https://orcid. org/0000-0003-0309-1473); Tae-Du Jung (https://orcid.org/0000-0002-1636-8665); Yang-Soo Lee (https://orcid.org/0000-0002-8855-1231).

() This is an open-access article distributed under the terms of the Creative Commons Attribution Non-Commercial License (http://creativecommons.org/ licenses/by-nc/4.0) which permits unrestricted noncommercial use, distribution, and reproduction in any medium, provided the original work is properly cited. Copyright $\odot 2018$ by Korean Academy of Rehabilitation Medicine 


\section{INTRODUCTION}

Stroke is one of the main causes of acquired physical disability in adults [1]. Paresis affecting the upper extremity is a common motor impairment in patients with stoke [2]. According to a previous study, $38 \%$ of patients with a paretic upper extremity regained limited dexterity at 6 months after stroke, whereas only $11.6 \%$ demonstrated complete functional recovery [3]. Dexterity, i.e., coordination of the fingers and manipulation of the objects, is important for most activities of daily living. The loss of hand dexterity often leads to limitations in activities of daily living, and may decrease the quality of life [4]. Therefore, improvements in dexterity for functional recovery and better quality of life are the main goals of rehabilitation in stroke patients with a paretic hand.

The measurement of dexterity or upper limb function is an important component of rehabilitation programs. A valid outcome measurement leads to more effective rehabilitation by quantifying the severity of disability, assisting in the development of a care plan, comparing the functional status between examination periods, and improving the efficiency of practice [5]. Many outcome measurements have been examined for the evaluation of upper limb function in patients with stroke, including the Jebsen-Taylor Hand Function Test (JTHFT) [6-9], FuglMeyer Assessment (FMA) [10-12], Box and Block Test (BBT) $[10,11,13-15]$, and Nine-Hole Peg Test $[6,11,13,16]$.

Button fastening requires fine and sequential coordination of the fingers and thumb, which is a skilled motor task that requires little attention, effort, or conscious control [17]. Clawson et al. [18] recorded the time taken to open and fasten six buttons that measured 0.75 inch in diameter and were mounted on a board placed in front of patients with rheumatoid arthritis to evaluate hand disability. This measurement was later modified to a standard board with five buttons by Pincus et al. [19], and these authors found excellent interobserver and intraobserver reliabilities for this test. The button fastening test was performed to evaluate hand function impairment in patients with Parkinson disease who showed a poor performance during a highly skilled movement [17]. This assessment was conducted by recording the time taken to fasten five buttons measuring $2.5 \mathrm{~cm}$ in diameter on a cardigan. The modified button fastening test was used by Nitz et al. [20] to assess hand disability in patients with myotonic dystrophy. Patients were instructed to fasten the lower four buttons that measured $6 \mathrm{~mm}$ in diameter on a standard shirt. The number of buttons fastened within 25 seconds, which was considered normal performance, was counted. In the aforementioned study, the buttoning test was performed with both hands, however, in a few studies, only the dominant hand was used to perform the test [21]. The buttoning test has been used to assess the hand function of patients with hand disability, but no standardized method has yet been established.

Although various outcome measurements previously mentioned including the JTHFT, highlight a stroke patient's dexterity, these tests require a specific tool and a certain amount of time. However, the buttoning test does not require a specific tool except clothing with buttons, and it can be performed quickly compared with other tests (within 2 minutes). This motor task is acquired in childhood and practiced throughout daily living, often without visual control and attention [17]. Therefore, the buttoning test can be performed by patients without a detailed explanation of the task.

Although this skilled motor task provides important information on hand disability in patients with various diseases, little information is available about the validity of the buttoning test, especially in patients with stroke. There are no standard methods and times required by non-impaired subjects to fasten a button.

The purpose of this study was to compare the relationship between the buttoning test and JTHFT, and to investigate the role of buttoning test as a valid measurement of hand disability in patients with stroke.

\section{MATERIALS AND METHODS}

\section{Participants}

Data were collected retrospectively from the medical records of patients who were diagnosed with ischemic stroke and hospitalized from January 2016 to April 2017 at the Kyungpook National University Hospital. Subjects were included if they had (1) a diagnosis of first ischemic stroke by a stroke neurologist, (2) computed tomography or magnetic resonance imaging data consistent with clinical presentation, (3) hemiparesis at the time of the tests, (4) paresis affecting the dominant hand determined by an interview on preference, (5) no evidence of cognitive impairment (Mini-Mental State Examination score 
$\geq 24$ ), and (6) the ability to follow 2 -step commands. Patients were excluded from the study if they had (1) musculoskeletal or other medical conditions that limited the affected upper extremity, (2) a history of stroke, (3) severe aphasia as evidenced by a score of 2 or 3 on the Language item of the National Institutes of Health Stroke Scale (NIHSS), or (4) complete hemianopsia as evidenced by a score of 2 or 3 on the visual item of the NIHSS.

This study was approved by the Institutional Review Board of Kyungpook National University Hospital (No. 2017-03-014).

\section{Clinical measurements}

All patients underwent the buttoning test and JTHFT, to quantify the severity of disability of their paretic hand.
Each patient was positioned in the sitting position as described by Nitz et al. [20]. They were seated in a chair with their feet flat on the floor, back fully supported by the backrest, and hands resting in their lap. In addition, to exclude the effect on the proximal upper limb strength, the forearm was fully supported by the lap and one button at hand height was used. Each patient was dressed in a standard patient gown with buttons that measured $1.2 \mathrm{~cm}$ in diameter and were attached down the front center, and the gown was large enough to fit all patients comfortably. The button was opened and patients were instructed to fasten the button as quickly as possible after they heard the command to 'start'. The button fastening time was measured from the start command until the successful completion of the task [17]. In this study, pa-

Table 1. Demographic and clinical characteristics $(n=206)$

\begin{tabular}{|c|c|c|c|}
\hline & DHA $(n=151)$ & NDHA $(n=55)$ & p-value \\
\hline Age (yr) & $61.8 \pm 11.5(37-89)$ & $64.9 \pm 10.8(19-88)$ & 0.08 \\
\hline Sex & & & 0.32 \\
\hline Male & $95(62.9)$ & $39(70.9)$ & \\
\hline Female & $56(37.1)$ & $16(29.1)$ & \\
\hline Time since stroke (day) & $8.0 \pm 15.2$ & $8.3 \pm 10.5$ & 0.89 \\
\hline Hand dominance & & & 0.45 \\
\hline Right & $143(94.7)$ & $54(98.2)$ & \\
\hline Left & $8(5.3)$ & $1(1.8)$ & \\
\hline Affected hemisphere & & & $<0.0001^{*}$ \\
\hline Right hemisphere & $12(7.9)$ & $53(96.4)$ & \\
\hline Left hemisphere & $139(92.1)$ & $2(3.6)$ & \\
\hline Location of the stroke lesion & & & 1.00 \\
\hline Supratentorial & $109(72.2)$ & $40(72.7)$ & \\
\hline Infratentorial & $42(27.8)$ & $15(27.3)$ & \\
\hline JTHFT, affected side & $53.4 \pm 28.3$ & $47.8 \pm 28.8$ & 0.21 \\
\hline \multicolumn{4}{|l|}{ NIHSS } \\
\hline Total score & $3.2 \pm 2.2$ & $3.8 \pm 2.7$ & 0.09 \\
\hline Visual item & $0.03 \pm 0.18$ & $0.09 \pm 0.29$ & 0.17 \\
\hline Motor arm item, affected side & $0.5 \pm 0.8$ & $0.6 \pm 0.8$ & 0.43 \\
\hline Language item & $0.04 \pm 0.20$ & $0.04 \pm 0.19$ & 0.91 \\
\hline \multicolumn{4}{|l|}{ Motricity Index } \\
\hline Arm, affected side & $59.8 \pm 33.3$ & $58.3 \pm 30.1$ & 0.93 \\
\hline MMSE-K & $26.8 \pm 2.3$ & $26.2 \pm 2.5$ & 0.57 \\
\hline
\end{tabular}

Values are presented as mean \pm standard deviation (range) or number (\%).

DHA, stroke patients with the dominant hand affected; NDHA, stroke patients with the non-dominant hand affected; JTHFT, Jebsen-Taylor Hand Function Test; NIHSS, National Institutes of Health Stroke Scale; MMSE-K, Mini-Mental State Examination-Korean version.

${ }^{*} \mathrm{p}<0.05$. 
tients were instructed to fasten the button with only their paretic hand to assess hand disability after stroke. The same procedure was used to test the button fastening ability of each patient.

All patients were divided into three groups depending on their execution of the task assigned (group A, not completed; group B, slowly completed over 18 seconds; and group $\mathrm{C}$, completed within 18 seconds). The time limit was determined as the upper limit required by agematched stroke patients with the non-dominant hand affected. It was determined by calculating the mean and the standard deviation (SD) from the time it took control patients to fasten a button using their unaffected dominant hand. Eighteen seconds was about the mean plus one SD (mean=10.2, SD=7.8). One trial of button fastening was performed for each measurement.

The JTHFT was performed by the method developed by Jebsen et al. [22]. The JTHFT is a functional assessment of the times required to complete seven common tasks: (1) writing a sentence, (2) simulated page turning, (3) picking up small objects, (4) simulated feeding, (5) stacking checkers, (6) picking up large, light objects, and (7) picking up large, heavy objects. The results were scored using the new scoring system with the mean and SD as described by Kim et al. [23].

\section{Statistical analyses}

Bivariate correlational analyses were used to examine the relationship of the JTHFT and buttoning test. We utilized the Pearson rank correlation coefficient (r) to examine the relation between the two outcome measures. The following criteria were employed to interpret the magnitude of the correlation coefficients: $<0.25$ indicated low, 0.25-0.5 indicated fair, 0.5-0.75 indicated moderate to good, and $>0.75$ indicated good to excellent [24].

The chi-square test and independent t-tests were used to compare characteristics between patients with the dominant hand affected and patients with the non-dominant hand affected.

The Jonckheere-Terpstra test was used to analyze an ordered difference in each group observed. The KruskalWallis test was used to analyze the mean difference in JTHFT scores among the groups to examine the discriminant validity of the buttoning test as an assessment of hand disability. Statistical significance was defined as $\mathrm{p}<0.05$. The Mann-Whitney U-test was used to determine

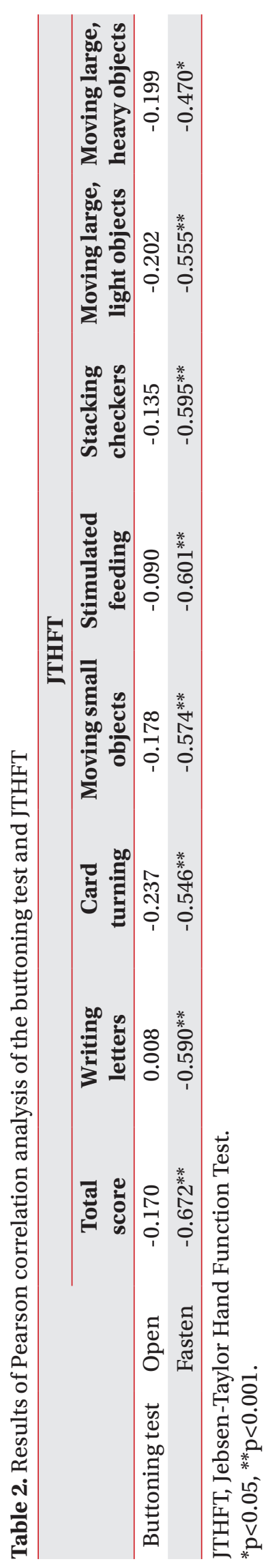


significant differences between the groups. Statistical significance was defined as $\mathrm{p}<0.017$. The subtest scores of JTHFT among the three test groups were also compared. All analyses were conducted with SPSS version 20.0 (IBM SPSS Inc., Armonk, NY, USA). We plotted the distributions of JTHFT scores within each buttoning test group using box plots, and inspected the minimum, maximum, average, and score range.

\section{RESULTS}

The analysis included 151 ischemic stroke patients with the dominant hand affected. The average age of individuals was $61.8 \pm 11.5$ years, and the average time since stroke was $8.0 \pm 15.2$ days. The sample had a greater proportion of men than women, $94.7 \%$ of them were right-handed, and $92.1 \%$ of patients had a lesion in the left hemisphere. Characteristics of patients with the dominant hand affected and patients with the non-dominant hand affected are listed in Table 1. No statistically significant differences between the groups were found for the following factors: age; sex; time since stroke; hand dominance; side of the affected hemisphere; location of the lesion; JTHFT; scores of total, visual, motor arm, and language items from the NIHSS; Motricity Index; and Mini-Mental State Examination-Korean version score.

Our results showed that the button fastening test was negatively correlated with the JTHFT $(\mathrm{p}<0.001)$ (Table 2). The correlation between the button fastening time and JTHFT was considered moderate-to-good $(\mathrm{r}=-\mathbf{0 . 6 7 2})$. The correlation between the button fastening time and each subtest of the JTHFT was evaluated. A fair-to-good correlation with statistical significance was found between the button fastening time and each subtest of the JTHFT: writing letters ( $\mathrm{r}=-0.590, \mathrm{p}<0.001)$, card turning $(\mathrm{r}=-0.546$, $\mathrm{p}<0.001)$, moving small objects $(\mathrm{r}=-0.574, \mathrm{p}<0.001)$, stimulated feeding $(r=-0.601, p<0.001)$, stacking check- ers $(\mathrm{r}=-0.595, \mathrm{p}<0.001)$, moving large light objects $(\mathrm{r}=-$ $0.555, \mathrm{p}<0.001)$, and moving large heavy objects $(\mathrm{r}=-0.470$, $\mathrm{p}<0.002)$. However, the button opening time was not statistically correlated with the total score and subtests of the JTHFT.

The JTHFT scores among the buttoning test groups are shown in Table 3. Fifty-two of 151 subjects (group A, $34.4 \%$ ) were unable to fasten the button with their paretic hand. Thirty patients (group C, 19.9\%) were able to fasten the button inside the 18-second time constraint. The patients who had difficulty with the buttoning test showed lower mean JTHFT scores $(\mathrm{p}<0.0001$, Jonckheere-Terpstra test). The Kruskal-Wallis test revealed significant differences in JTHFT scores among the three buttoning test groups $(\mathrm{p}<0.0001)$. The Mann-Whitney U-test indicated that all pairs of groups were significantly different from each other $(\mathrm{p}<0.017$ level).

The distribution of the JTHFT scores in each buttoning test group is shown in Fig. 1. There were considerable overlaps in JTHFT scores between the buttoning test

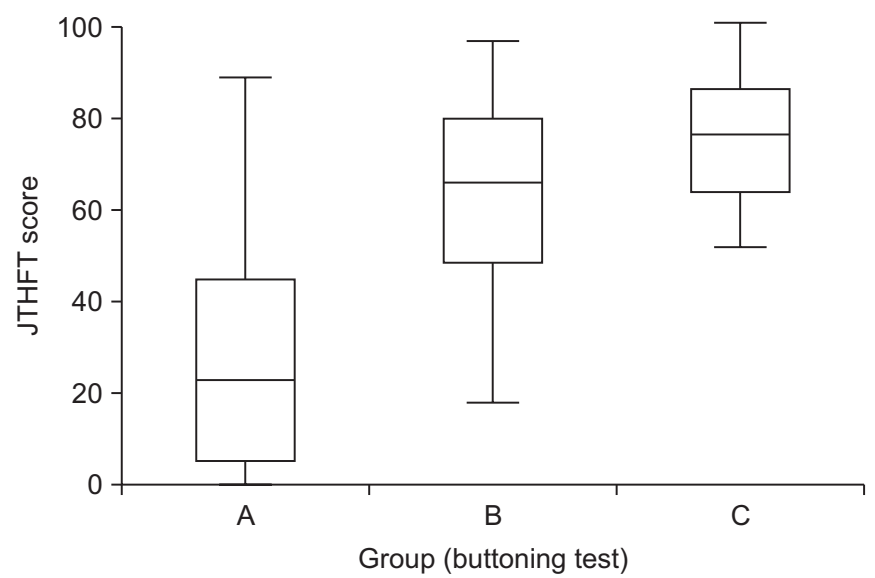

Fig. 1. Distribution of the Jebsen-Taylor Hand Function Test (JTHFT) scores for each buttoning test group. It shows the maximum, upper quartile, median, lower quartile, and minimum values of the JTHFT scores.

Table 3. JTHFT scores of the buttoning test groups

\begin{tabular}{cccccccc}
\hline & Group A & Group B & Group C & \multicolumn{4}{c}{ p-value } \\
\cline { 6 - 8 } & $(\mathbf{n}=\mathbf{5 2})$ & $(\mathbf{n}=\mathbf{6 9})$ & $(\mathbf{n}=\mathbf{3 0})$ & Among groups & A-B & A-C & B-C \\
\hline JTHFT & $28.0 \pm 23.9$ & $62.9 \pm 21.7$ & $75.4 \pm 13.3$ & $<0.0001^{*}$ & $<0.0001^{* *}$ & $<0.0001^{* *}$ & $0.01^{* *}$
\end{tabular}

Values are presented as a mean \pm standard deviation.

JTHFT, Jebsen-Taylor Hand Function Test.

${ }^{*} \mathrm{p}<0.05$, Kruskal-Wallis test.

**p $<0.017$, Mann-Whitney U-test. 
Table 4. Subtest scores of JTHFT in the buttoning test groups

\begin{tabular}{lccccccc}
\hline & \multicolumn{7}{c}{ JTHFT } \\
\cline { 2 - 8 } & $\begin{array}{c}\text { Writing } \\
\text { letters }\end{array}$ & $\begin{array}{c}\text { Card } \\
\text { turning }\end{array}$ & $\begin{array}{c}\text { Moving } \\
\text { small objects }\end{array}$ & $\begin{array}{c}\text { Stimulated } \\
\text { feeding }\end{array}$ & $\begin{array}{c}\text { Stacking } \\
\text { checkers }\end{array}$ & $\begin{array}{c}\text { Moving } \\
\text { large, light } \\
\text { objects }\end{array}$ & $\begin{array}{c}\text { Moving } \\
\text { large, heavy } \\
\text { objects }\end{array}$ \\
\hline Group A & $4.2 \pm 4.0^{* *}$ & $2.2 \pm 2.4^{* *}$ & $2.5 \pm 3.7^{* *}$ & $5.3 \pm 4.5^{* *}$ & $4.6 \pm 4.3^{* *}$ & $4.5 \pm 3.9^{* *}$ & $4.8 \pm 4.1^{* *}$ \\
Group B & $9.4 \pm 4.1$ & $6.2 \pm 3.9$ & $8.0 \pm 3.9$ & $11.4 \pm 3.1$ & $9.5 \pm 3.3$ & $9.1 \pm 3.6$ & $9.3 \pm 3.4$ \\
Group C & $11.8 \pm 2.5^{* *}$ & $7.5 \pm 3.4$ & $10.4 \pm 2.8^{* *}$ & $12.6 \pm 2.2$ & $11.6 \pm 2.1^{* *}$ & $10.9 \pm 2.4$ & $10.6 \pm 2.1$ \\
\hline p-value among groups & $<0.0001^{*}$ & $<0.0001^{*}$ & $<0.0001^{*}$ & $<0.0001^{*}$ & $<0.0001^{*}$ & $<0.0001^{*}$ & $<0.0001^{*}$ \\
\hline
\end{tabular}

Values are presented as a mean \pm standard deviation.

JTHFT, Jebsen-Taylor Hand Function Test.

${ }^{*} \mathrm{p}<0.05$, Kruskal-Wallis test.

** $\mathrm{p}<0.017$ versus group B, Mann-Whitney U-test.

groups, especially in groups B and C.

There were also significant differences between groups $A$ and $B$, and between groups $A$ and $C$ in all subtest scores of the JTHFT $(p<0.0001)$. Significant differences were observed between groups $\mathrm{B}$ and $\mathrm{C}$ in writing letters $(\mathrm{p}=0.090)$, moving small objects $(\mathrm{p}=0.003)$, and stacking checkers $(\mathrm{p}=0.001)$, which involve fine hand motor function (Table 4).

\section{DISCUSSION}

Assessment of the ability to fasten buttons provides the physician or occupational therapist with an overview of a patient's hand function $[17,20,25]$. Hand disability is a common motor impairment in patients [2]. However, little information is available concerning the validity of the buttoning test for patients with stroke.

Button fastening involves a more skilled, complex motor task than button opening. In this study, the magnitude of correlation between the button fastening test and JTFHT was higher than between the button opening test and JTFHT. We examined for statistical differences in mean JTHFT scores among the button fastening test levels to identify the discriminant validity of the buttoning test as an assessment of hand disability. There were significant differences in JTHFT scores among the three study groups. Results of the Mann-Whitney U-test showed that all pairs of groups (A-B, A-C, and B-C) were significantly different from each other $(\mathrm{p}<0.017)$. Moreover, the more difficult it was to fasten the button, the lower the JTHFT score was $(\mathrm{p}<0.0001$, Jonckheere-Terpstra test). These results support the validity of the button fastening test as a hand disability test after stroke.

Nitz et al. [20] reported that the button fastening ability was related to muscle strength of the proximal upper limb in patients with myotonic dystrophy. Therefore, upper limb posture is important to exclude the effect of proximal upper limb weakness and to perform the hand action. All patients sat upright with the shoulder joint adducted, elbow joint flexed, and forearm fully supported on the lapboard. We assessed only one button at the same level of the hand that was placed on the lapboard. In this study, the motor arm item that represented proximal upper limb strength in the NIHSS was not statistically correlated with the button fastening time $(\mathrm{r}=0.227$, $\mathrm{p}=0.159$ ), although it was correlated with the JTHFT score $(\mathrm{r}=-0.603, \mathrm{p}<0.001)$. This different result may be attributed to the method of the buttoning test that minimizes the contribution of the proximal upper limb. Our results suggest that the buttoning test can be used as a measure of hand dysfunction rather than the entire upper limb in patients with stroke.

Subtests of the JTHFT requiring fine hand function, such as writing letters, moving small objects, and stacking checkers, showed statistically significant differences among the three buttoning groups. These results were consistent with the need for fine, sequential, and bimanual coordination skills of the fingers and thumb [17]. The button test can be considered as a test that more closely reflects the fine motor function than the gross motor function.

Cognitive dysfunction altered consciousness, severe aphasia, and visual disturbance may have a detrimental effect on functional performance in patients with stroke, 
and may affect the outcome of hand function measures. However, button testing has been identified as an automatic process that requires little conscious control, attention, and resources [17]. The timed button fastening task was not correlated with the degree of visual, spatial, or cognitive dysfunction [26]. Although our study excluded stroke patients with cognitive impairment, severe aphasia, complete hemianopsia, and inability to follow 2 -step commands, further studies that include patients with these impairments may need to reinforce the utility of buttoning test as a measure of hand function in variable degrees of impairment in patients with stroke.

Advantages of the buttoning test are its relative simplicity and the shorter time required for administration compared with other outcome measurements of hand disability. If the goal is to obtain a more comprehensive assessment of dexterity, the JTHFT may be the preferred option. However, only 2 minutes and a hospital gown with buttons are needed to perform the buttoning test. Therefore, this measurement is advantageous in clinical settings such as clinical rounds and in outpatient clinics, where time and resources are limited. In this study, one standardized gown was used; however, under the clinical settings, various sizes of buttons and buttonholes can be used, and the difficulty of button fastening can vary depending on the nature of the buttonhole, which may affect the normality criterion and degree of reflection associated with hand disability. Further studies will be needed to confirm whether the buttoning test using nonstandardized gowns is useful as a screening test to identify hand disability.

An easy evaluation of hand disability requires three levels of grading. However, the range of JTHFT scores in all buttoning test groups was wide, with considerable overlaps between the groups, possibly due to the concise grading system of the buttoning test. Additionally, although the buttoning test showed good reliability [19], one trial of button fastening was performed for each measurement causing the overlapped distribution. To avoid these issues, a grading system based on further information of the standard time required by non-impaired subjects to fasten a button and repeated button fastening may be a solution.

When the results of this study are interpreted, some potential limitations warrant consideration. First, our sample size was small $(n=30)$ for group C. The small sample size reduced statistical power in the correlational analyses and validity test. Second, we did not compare the buttoning test with other tests such as the FMA and BBT for evaluating hand disability, and Modified Barthel Index for evaluating activities of daily living in patients with stroke. Third, this study did not include patients with hemorrhagic stroke that accounted for a large number of stroke patients. Forth, there was little follow-up data available and the role of button test in assessing hand function improvement during stroke recovery could not be confirmed.

Despite the findings supporting the merits of buttoning test, a further study involving a larger sample with a broader range of stroke-related impairments in dexterity should include patients with hemorrhagic stroke, and non-impaired subjects. A longitudinal follow-up evaluation is also needed.

In summary, the buttoning test was selected as an outcome measurement of hand disability in patients with stroke. This test was significantly and negatively correlated with the JTHFT and represents a valid measurement tool. Furthermore, the results of this study suggest that the buttoning test was more appropriate for the evaluation of fine hand motor function. The 2-minute time required to perform this assessment may be of considerable value in a clinical setting. This study did not account for the overlapped distribution between the buttoning groups and precise grading references, suggesting the need for a further study with a larger sample to validate the finding.

\section{CONFLICT OF INTEREST}

No potential conflict of interest relevant to this article was reported.

\section{REFERENCES}

1. Langhorne P, Bernhardt J, Kwakkel G. Stroke rehabilitation. Lancet 2011;377:1693-702.

2. Parker VM, Wade DT, Langton Hewer R. Loss of arm function after stroke: measurement, frequency, and recovery. Int Rehabil Med 1986;8:69-73.

3. Kwakkel G, Kollen BJ, van der Grond J, Prevo AJ. Probability of regaining dexterity in the flaccid upper limb: impact of severity of paresis and time since onset in 
acute stroke. Stroke 2003;34:2181-6.

4. Nichols-Larsen DS, Clark PC, Zeringue A, Greenspan A, Blanton S. Factors influencing stroke survivors' quality of life during subacute recovery. Stroke 2005; 36:1480-4.

5. Sullivan JE, Crowner BE, Kluding PM, Nichols D, Rose DK, Yoshida R, et al. Outcome measures for individuals with stroke: process and recommendations from the American Physical Therapy Association neurology section task force. Phys Ther 2013;93:1383-96.

6. Beebe JA, Lang CE. Relationships and responsiveness of six upper extremity function tests during the first six months of recovery after stroke. J Neurol Phys Ther 2009;33:96-103.

7. Hummel F, Celnik P, Giraux P, Floel A, Wu WH, Gerloff $\mathrm{C}$, et al. Effects of non-invasive cortical stimulation on skilled motor function in chronic stroke. Brain 2005; 128(Pt 3):490-9.

8. Duncan P, Richards L, Wallace D, Stoker-Yates J, Pohl P, Luchies $\mathrm{C}$, et al. A randomized, controlled pilot study of a home-based exercise program for individuals with mild and moderate stroke. Stroke 1998;29:205560.

9. Han TR, Yoon KJ, Jung SH. The chronological review of uninvolved hand function in stroke patients. J Korean Acad Rehabil Med 2004;28:13-9.

10. Hsieh YW, Wu CY, Lin KC, Chang YF, Chen CL, Liu JS. Responsiveness and validity of three outcome measures of motor function after stroke rehabilitation. Stroke 2009;40:1386-91.

11. Platz T, Pinkowski C, van Wijck F, Kim IH, di Bella P, Johnson G. Reliability and validity of arm function assessment with standardized guidelines for the FuglMeyer Test, Action Research Arm Test and Box and Block Test: a multicenter study. Clin Rehabil 2005;19: 404-11.

12. Rabadi MH, Rabadi FM. Comparison of the action research arm test and the Fugl-Meyer assessment as measures of upper-extremity motor weakness after stroke. Arch Phys Med Rehabil 2006;87:962-6.

13. Chen HM, Chen CC, Hsueh IP, Huang SL, Hsieh CL. Test-retest reproducibility and smallest real difference of 5 hand function tests in patients with stroke. Neurorehabil Neural Repair 2009;23:435-40.

14. Higgins J, Mayo NE, Desrosiers J, Salbach NM, Ahmed
S. Upper-limb function and recovery in the acute phase poststroke. J Rehabil Res Dev 2005;42:65-76.

15. Higgins J, Salbach NM, Wood-Dauphinee S, Richards CL, Cote R, Mayo NE. The effect of a task-oriented intervention on arm function in people with stroke: a randomized controlled trial. Clin Rehabil 2006;20:296310.

16. Croarkin E, Danoff J, Barnes C. Evidence-based rating of upper-extremity motor function tests used for people following a stroke. Phys Ther 2004;84:62-74.

17. Soliveri P, Brown RG, Jahanshahi M, Marsden CD. Effect of practice on performance of a skilled motor task in patients with Parkinson's disease. J Neurol Neurosurg Psychiatry 1992;55:454-60.

18. Clawson DK, Souter WA, Carthum CJ, Hymen ML. Functional assessment of the rheumatoid hand. Clin Orthop Relat Res 1971;77:203-10.

19. Pincus T, Brooks RH, Callahan LF. Reliability of grip strength, walking time and button test performed according to a standard protocol. J Rheumatol 1991;18: 997-1000.

20. Nitz J, Burns Y, Jackson R. The validity of button fastening as a test of hand disability in myotonic dystrophy. Aust J Physiother 1998;44:117-21.

21. Pincus T, Brooks RH, Callahan LF. Prediction of longterm mortality in patients with rheumatoid arthritis according to simple questionnaire and joint count measures. Ann Intern Med 1994;120:26-34.

22. Jebsen RH, Taylor N, Trieschmann RB, Trotter MJ, Howard LA. An objective and standardized test of hand function. Arch Phys Med Rehabil 1969;50:311-9.

23. Kim JH, Kim IS, Han TR. New scoring system for jebsen hand function test. J Korean Acad Rehabil Med 2007;31:623-9.

24. Portney LG, Watkins MP. Foundations of clinical research: applications to practice. 2nd ed. Upper Saddle River: Prentice-Hall; 2000.

25. Pincus T. Rheumatology function tests: quantitative physical measures to monitor morbidity and predict mortality in patients with rheumatic diseases. Clin Exp Rheumatol 2005;23(5 Suppl 39):S85-9.

26. Johnson ER, Abresch RT, Carter GT, Kilmer DD, Fowler WM Jr, Sigford BJ, et al. Profiles of neuromuscular diseases: myotonic dystrophy. Am J Phys Med Rehabil 1995;74(5 Suppl):S104-16. 